\title{
Burden of cardiovascular risk factors and disease among patients with type 1 diabetes: results of the Australian National Diabetes Audit (ANDA)
}

Anthony Pease ${ }^{1,2}$, Arul Earnest ${ }^{1}$, Sanjeeva Ranasinha ${ }^{1}$, Natalie Nanayakkara ${ }^{1,2}$, Danny Liew ${ }^{1}$, Natalie Wischer ${ }^{1}$, Sofianos Andrikopoulos ${ }^{1,3}$ and Sophia Zoungas ${ }^{1,2^{*}}$

\begin{abstract}
Background: Cardiovascular risk stratification is complex in type 1 diabetes. We hypothesised that traditional and diabetes-specific cardiovascular risk factors were prevalent and strongly associated with cardiovascular disease (CVD) among adults with type 1 diabetes attending Australian diabetes centres.

Methods: De-identified, prospectively collected data from patients with type 1 diabetes aged $\geq 18$ years in the 2015 Australian National Diabetes Audit were analysed. The burden of cardiovascular risk factors [age, sex, diabetes duration, glycated haemoglobin (HbA1c), blood pressure, lipid profile, body mass index, smoking status, retinopathy, renal function and albuminuria] and associations with CVD inclusive of stroke, myocardial infarction, coronary artery bypass graft surgery/angioplasty and peripheral vascular disease were assessed. Restricted cubic splines assessed for nonlinearity of diabetes duration and likelihood ratio test assessed for interactions between age, diabetes duration, centre type and cardiovascular outcomes of interest. Discriminatory ability of multivariable models were assessed with area under the receiver operating characteristic (ROC) curves.
\end{abstract}

Results: Data from 1169 patients were analysed. Mean ( \pm SD) age and median diabetes duration was 40.0 ( \pm 16.7 ) and 16.0 (8.0-27.0) years respectively. Cardiovascular risk factors were prevalent including hypertension (21.9\%), dyslipidaemia (89.4\%), overweight/obesity (56.4\%), ever smoking (38.5\%), albuminuria (31.1\%), estimated glomerular filtration rate $<60 \mathrm{~mL} / \mathrm{min} / 1.73 \mathrm{~m}^{2}(10.3 \%)$ and $\mathrm{HbA1c}>7.0 \%$ (53 mmol/mol) (81.0\%). Older age, longer diabetes duration, smoking and antihypertensive therapy use were positively associated with CVD, while high density lipoproteincholesterol and diastolic blood pressure were negatively associated $(p<0.05)$. Association with CVD and diabetes duration remained constant until 20 years when a linear increase was noted. Longer diabetes duration also had the highest population attributable risk of $6.5 \%(95 \% \mathrm{Cl} 1.4,11.6)$. Further, the models for CVD demonstrated good discriminatory ability (area under the ROC curve $0.88 ; 95 \% \mathrm{Cl} 0.84,0.92$ ).

Conclusions: Cardiovascular risk factors were prevalent and strongly associated with CVD among adults with type 1 diabetes attending Australian diabetes centres. Given the approximate J-shaped association between type 1 diabetes duration and CVD, the impact of cardiovascular risk stratification and management before and after 20 years duration needs to be further assessed longitudinally. Diabetes specific cardiovascular risk stratification tools incorporating diabetes duration should be an important consideration in future guideline development.

Keywords: Type 1 diabetes mellitus, Cardiovascular disease, Epidemiology

\footnotetext{
*Correspondence: sophia.zoungas@monash.edu

${ }^{1}$ School of Public Health and Preventive Medicine, Monash University, 5th Floor, The Alfred Centre, 99 Commercial Road, Melbourne, VIC 3004,

Australia

Full list of author information is available at the end of the article
} 


\section{Background}

Cardiovascular disease (CVD) is the leading cause of death among people with type 1 diabetes [1-6]. Furthermore, people with type 1 diabetes experience cardiovascular events about 10 years earlier than a matched population without diabetes [7]. This is juxtaposed with current national strategies in primary prevention of CVD that focus on absolute cardiovascular risk stratification from around 40 years of age regardless of comorbidities $[1,8-11]$. This strategy fails to integrate the duration of exposure to risk factors which may be of particular relevance to younger people diagnosed with type 1 diabetes in their youth.

While traditional cardiovascular risk factors are expected to contribute to the observed increased risk of CVD, the relative strength of associations in type 1 diabetes is not clear. The protective association of female sex with CVD, for example, appears to be negated in at least those women aged less than 40 years with type 1 diabetes $[5,12,13]$. Similarly, while obesity is recognised as an independent risk factor for CVD in the general population [14-18], the impact of increasing body mass index (BMI) in type 1 diabetes is not firmly established. Furthermore, recommendations for pharmacotherapy to manage risk factors are largely extrapolated from trials in adults with type 2 diabetes that may not be generalisable to those with type 1 diabetes $[1,8,9,19]$.

Understanding relationships between risk factors and cardiovascular outcomes is pivotal for informing preventive strategies. Current risk stratification models utilise traditional cardiovascular risk factors from risk equations, which have been extensively validated in the general population [1, 8-10]. However, this approach has been shown to be a poor predictor of cardiovascular events in adults with type 1 diabetes, generally underestimating risk in this group $[1,9,20]$. Risk stratification models specifically for adults with type 1 diabetes as well as investigational biomarkers have been developed but are not in widespread clinical use [21-26]. Elements of these models that differ from those currently recommended include consideration of diabetes duration, glycaemic control (HbA1c) and albuminuria [21-23]. However, there is a paucity of contemporary data on the prevalence of cardiovascular risk factors and disease among people with type 1 diabetes. Follow-up of the landmark diabetes control and complications trial cohort also suggests there may be gaps in managing cardiovascular risk factors as only $7.6 \%$ attained all four of the American Diabetes Association recommendations for complication prevention [27]. Until further studies can corroborate any associations and the reliability of new risk stratification models, only individual risk factor assessment and clinical judgment can direct clinical care.
We thus examined the burden of cardiovascular risk factors and their associations with cardiovascular complications among patients with type 1 diabetes attending diabetes centres across Australia. Traditionally considered and diabetes specific cardiovascular risk factors were hypothesised to be prevalent and strongly associated with CVD in this vulnerable population.

\section{Methods \\ Subjects}

The Australian National Diabetes Audit (ANDA) is an annual cross-sectional benchmarking activity including patients of all ages and diabetes types. Diabetes centres voluntarily participate, with approximately two-thirds being tertiary centres and one-third primary or community based centres. De-identified data for our study were collected across all centres during a 1-month survey period in May or June (2015) for all consecutive patients. Patients considered for this analysis were adults $(\geq 18$ years) with type 1 diabetes $(n=1169)$ presenting to one of the 49 participating diabetes centres. The degree of patient ascertainment could not be determined because only data for those participants involved in the study were collected.

Ethical approval for our study was provided by the Monash Health Human Research Ethics Committee.

\section{Data collection}

Relevant pre-specified sociodemographic (date of birth, date of diabetes diagnoses, sex, Aboriginal/Torres Strait Islander ethnicity) and clinical variables (diabetes type, weight, height, smoking status, blood pressure (BP), lipid levels, urinary albumin, serum creatinine, HbA1c, lipid lowering medications, antihypertensive medications, diabetes complications, comorbid conditions) were collected. Health care professionals participating in ANDA examined patients, reviewed medical records including pathology results during standard patient consultations and recorded the de-identified information in a standardised collection form (Additional file 1). The participating centres were later contacted to clarify missing data and invalid entries.

\section{Variables}

Age was calculated as the date of questionnaire (in 2015) minus the date of birth, and diabetes duration was calculated as the date of questionnaire minus the date of diabetes diagnosis. Provided height and weight measurements were used to calculate the BMI in $\mathrm{kg} / \mathrm{m}^{2}$. The main outcome variables for this analysis were cerebral stroke, myocardial infarction (MI), coronary artery bypass graft (CABG) surgery/angioplasty, peripheral vascular disease (PVD) and the composite of these atherosclerotic 
outcomes defining CVD. PVD was defined clinically as the absence of both the dorsalis pedis and posterior tibialis pulses on either foot or amputation of toe, forefoot or leg (above or below knee), not due to trauma or causes other than vascular disease. An additional outcome of interest was congestive cardiac failure (CCF) defined by clinician determined symptomatic status and responsiveness to therapy. The healthcare professional completing the questionnaire determined the presence of these complications and other comorbid conditions with access to a data dictionary of terms provided by the ANDA secretariat prior to commencing the questionnaire (Additional file 2). Cardiovascular risk factors considered in analysis include sex, age, diabetes duration, HbA1c, BMI categories, smoking status (ever smoked versus never smoked), systolic blood pressure, diastolic blood pressure, albuminuria $(>20.0 \mathrm{mg} / \mathrm{L},>20.0 \mu \mathrm{g} / \mathrm{min},>30.0 \mathrm{mg} / 24 \mathrm{~h}$, or $>2.5 \mathrm{mg} / \mathrm{mmol}$ for women and $>3.5 \mathrm{mg} / \mathrm{mmol}$ for men), presence of retinopathy, high density lipoproteincholesterol (HDL-C) and estimated glomerular filtration rate (eGFR) calculated using the chronic kidney disease epidemiology collaboration (CKD-EPI) formula based on sex and collected creatinine values in $\mu \mathrm{mol} / \mathrm{L}$ [28]. The eGFR was not adjusted for ethnicity among Aboriginal or Torres Strait Islander (ATSI) people groups in keeping with current literature [29-31], and no other ethnicity data was collected. Total cholesterol, low density lipoprotein-cholesterol (LDL-C) and triglycerides were excluded from regression analyses a priori. BMI categories were considered as underweight $(<18.5 \mathrm{~kg} /$ $\mathrm{m}^{2}$ ), normal weight $\left(18.5\right.$ to $\left.<25.0 \mathrm{~kg} / \mathrm{m}^{2}\right)$, overweight $\left(25.0\right.$ to $\left.<30.0 \mathrm{~kg} / \mathrm{m}^{2}\right)$ and obese $\left(\geq 30.0 \mathrm{~kg} / \mathrm{m}^{2}\right)$. Dyslipidaemia was defined as failure to meet current Australian treatment targets (i.e. total cholesterol $\geq 4.0 \mathrm{mmol} / \mathrm{L}$, $\mathrm{HDL}-\mathrm{C}<1.0 \mathrm{mmol} / \mathrm{L}, \mathrm{LDL}-\mathrm{C} \geq 2.0 \mathrm{mmol} / \mathrm{L}$ or triglycerides $\geq 2.0 \mathrm{mmol} / \mathrm{L}$ ). Hypertension was defined as systolic blood pressure $\geq 140 \mathrm{mmHg}$ or diastolic blood pressure $\geq 90 \mathrm{mmHg}$. Retinopathy was recorded as absent or present for the preceding 12 months. Diabetes centre type corresponds to secondary or community/primary centres derived from the category of membership with the National Association of Diabetes Centres (NADC). Secondary centres comprised centres of excellence and tertiary diabetes centres, and community/primary centres comprise affiliate and diabetes care centres.

\section{Statistical analysis}

Continuous data were tested for normality of distribution and summarised as means with standard deviations $( \pm \mathrm{SD})$ or medians with interquartile range (IQR; 25th75 th percentile). When comparing means or medians we used the Student's $t$ test or Mann-Whitney U test respectively. Categorical variables were summarised as participant numbers and percentages, and when comparing between groups we used the Chi square test. Restricted cubic splines were utilised to evaluate nonlinear associations between cardiovascular outcomes and diabetes duration. Scoping review and expert opinion lead to selection of knots at 5.0, 15.0, 25.0 and 35.0 years duration. The binary logistic regression model was used to examine the association of risk factors with cardiovascular outcomes of interest and likelihood ratio test assessed for interactions between age and diabetes duration as well as diabetes centre type. The selection of variables was based on identifying all measured clinical variables of known or suspected prognostic importance for the outcomes of interest and/or exhibiting a $p$ value $\leq 0.1$ on univariable analysis. Age and sex were forced into all multivariable models as they were considered clinically significant a priori. Models also adjusted for antihypertensive and lipid lowering therapy. Multivariable regression analyses were performed for each cardiovascular outcome of interest using stepwise selection of variables (1\% probability for entry and $5 \%$ probability for removal) for the remaining predictor variables. Based on the coefficients from the final parsimonious multivariable model, we calculated the ROC curve and 95\% confidence intervals. Population attributable risk (PAR) and 95\% confidence intervals were calculated for each significant categorical variable from the final multivariable models under the assumption that associations were causal [32]. Multiple imputation was performed for missing data (Additional file 3: Table S1 and Additional file 4: Table S2 respectively). Statistical analyses were performed using Stata software version 14.2 (StataCorp, Texas, USA) and level of significance set at $5 \%$ unless otherwise specified.

\section{Results}

\section{Patient characteristics}

Data from 1169 patients were included in this study. Cardiovascular risk factors were highly prevalent, including hypertension (21.9\%), dyslipidaemia (89.4\%), overweight or obesity $(56.4 \%)$, ever smoking (38.5\%), albuminuria (31.1\%), eGFR $<45 \mathrm{~mL} / \mathrm{min} / 1.73 \mathrm{~m}^{2}(6.5 \%)$ or $<60 \mathrm{~mL} /$ $\mathrm{min} / 1.73 \mathrm{~m}^{2}$ (10.3\%) and HbA1c exceeding 7.0\% (81.0\%). Patients with CVD tended to be male (61.5\%) with a mean age of $58.5 \pm 13.7$ years. Median diabetes duration was 35.0 (24.5-45.0) years, mean HbA1c was $8.6 \pm 1.5 \%$ and the mean HDL-C was $1.35 \pm 0.42 \mathrm{mmol} / \mathrm{L}$. Most patients with CVD were overweight/obese (56.4\%), had smoked $(64.2 \%)$ or had retinopathy $(56.2 \%)$. The mean eGFR for patients with CVD was $71( \pm 29) \mathrm{mL} /$ $\min / 1.73 \mathrm{~m}^{2}$ and around half of the patients with CVD had albuminuria (47.9\%). Secondary prevention prescribing of lipid lowering therapy and antihypertensive therapy was noted in up to 75.3 and $72.9 \%$ respectively. Mean 
systolic and diastolic blood pressure levels were $132 \pm 21$ and $72 \pm 10 \mathrm{mmHg}$ respectively. A summary of cardiovascular outcomes with risk factor levels is provided in Table 1 and Additional file 5: Table S3a and b.

\section{Cardiovascular complications}

A non-linear association between diabetes duration and CVD was demonstrated (Fig. 1). Odds of CVD were low and static until approximately 20 years duration, at which point a positive linear association emerged (Fig. 1). As a categorical variable, diabetes duration $\geq 20.0$ years was significantly associated with the composite outcome of CVD (no interaction with age; likelihood ratio test p-value 0.816) in multivariable analysis [adjusted odds ratio (aOR) 1.05 (95\% CI 1.01, 1.10); p 0.018] (Table 2).

Increasing age [aOR 1.06 (95\% CI 1.03, 1.09)], diabetes duration $\geq 20.0$ years [aOR 1.05 (95\% CI 1.01 , 1.10)], smoking status [aOR 2.40 (95\% CI 1.26, 4.58)] and prescription of antihypertensive therapy [aOR $2.44(95 \%$ CI $1.15,5.18)]$ were all positively associated

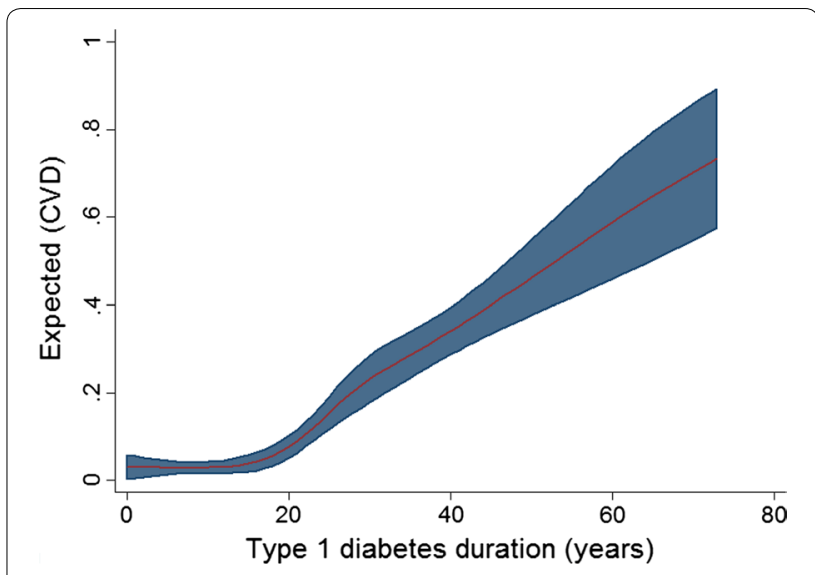

Fig. 1 Restricted cubic spline of type 1 diabetes duration and cardiovascular disease

with CVD. Increasing HDL-C and diastolic blood pressure were negatively associated with CVD [aOR 0.43 (95\% CI 0.21, 0.90) and aOR 0.96 (95\% CI 0.93-1.00)

Table 1 Distribution of variables for cardiovascular outcomes of interest

\begin{tabular}{|c|c|c|c|c|}
\hline \multirow[t]{2}{*}{ Variables } & \multicolumn{3}{|c|}{ Cardiovascular outcomes of interest } & \multirow[t]{2}{*}{ p-value } \\
\hline & $\begin{array}{l}\text { Total } \\
\mathrm{N}=1169\end{array}$ & $\begin{array}{l}\text { CVD } \\
N=148\end{array}$ & $\begin{array}{l}\text { No CVD } \\
N=1013\end{array}$ & \\
\hline Female sex, n (\%) & $609(53.3 \%)$ & $57(38.5 \%)$ & $550(55.7 \%)$ & $<0.001$ \\
\hline Age (years), mean $( \pm S D)$ & $40.0( \pm 16.7)$ & $58.5( \pm 13.7)$ & $37.3( \pm 15.4)$ & $<0.001$ \\
\hline Age (years), median (IQR) & $37.0(24.9-52.0)$ & $59.0(49.0-68.2)$ & $33.8(23.9-47.2)$ & $<0.001$ \\
\hline Diabetes duration (years), mean (SD) & $19.2( \pm 14.4)$ & $34.8( \pm 15.5)$ & $17.1( \pm 12.8)$ & $<0.001$ \\
\hline Diabetes duration (years), median (IQR) & $16.0(8.0-27.0)$ & $35.0(24.5-45.0)$ & $15.0(8.0-24.0)$ & $<0.001$ \\
\hline Diabetes duration ( $\geq 20.0$ years), $\mathrm{n}(\%)$ & $476(41.3 \%)$ & $121(84.0 \%)$ & $354(35.4 \%)$ & $<0.001$ \\
\hline $\mathrm{HbA1c}(\%)$, mean $( \pm \mathrm{SD})$ & $8.5( \pm 1.8)$ & $8.6( \pm 1.5)$ & $8.5( \pm 1.9)$ & 0.386 \\
\hline $\mathrm{HDL}-\mathrm{C}^{\mathrm{a}}$, mean $( \pm \mathrm{SD})$ & $1.53( \pm 0.54)$ & $1.35( \pm 0.42)$ & $1.56( \pm 0.56)$ & $<0.001$ \\
\hline LDL-C ${ }^{\mathrm{a}}$, mean $( \pm S D)$ & $2.55( \pm 0.95)$ & $2.15( \pm 0.82)$ & $2.62( \pm 0.95)$ & $<0.001$ \\
\hline Total- $C^{\mathrm{a}}$, mean $( \pm S D)$ & $4.73( \pm 1.09)$ & $4.18( \pm 1.12)$ & $4.83( \pm 1.06)$ & $<0.001$ \\
\hline Triglycerides ${ }^{\mathrm{a}}$, mean $( \pm \mathrm{SD})$ & $1.37( \pm 1.42)$ & $1.54( \pm 1.84)$ & $1.34( \pm 1.34)$ & 0.190 \\
\hline Systolic BPb, mean ( \pm SD) & $124( \pm 17)$ & $132( \pm 21)$ & $123( \pm 16)$ & $<0.001$ \\
\hline Diastolic BPb ${ }^{b}$ mean $( \pm S D)$ & $74( \pm 10)$ & $72( \pm 10)$ & $74( \pm 10)$ & 0.073 \\
\hline BMl categories, $\mathrm{n}(\%)\left(\mathrm{kg} / \mathrm{m}^{2}\right)$ & & & & 0.372 \\
\hline$<18.5$ & $20(2.0 \%)$ & $4(3.2 \%)$ & $15(1.7 \%)$ & \\
\hline 18.5 to $<25$ & $419(41.6 \%)$ & $51(40.5 \%)$ & $365(41.8 \%)$ & \\
\hline 25 to $<30$ & $315(31.3 \%)$ & $34(27.0 \%)$ & 279 (31.9\%) & \\
\hline$\geq 30$ & $253(25.1 \%)$ & $37(29.4 \%)$ & $215(24.6 \%)$ & \\
\hline Ever smoked, n (\%) & $397(38.5 \%)$ & $86(64.2 \%)$ & $309(34.6 \%)$ & $<0.001$ \\
\hline Albuminuria, n (\%) & $220(31.1 \%)$ & $46(47.9 \%)$ & $174(28.6 \%)$ & $<0.001$ \\
\hline eGFR', mean $( \pm S D)$ & $97( \pm 28)$ & $71( \pm 29)$ & $101( \pm 25)$ & $<0.001$ \\
\hline Antihypertensive Rx, n (\%) & $320(28.1 \%)$ & $105(72.9 \%)$ & $214(21.7 \%)$ & $<0.001$ \\
\hline Lipid lowering Rx, n (\%) & $342(29.7 \%)$ & $110(75.3 \%)$ & $232(23.2 \%)$ & $<0.001$ \\
\hline Retinopathy, n (\%) & $284(24.7 \%)$ & $82(56.2 \%)$ & $202(20.2 \%)$ & $<0.001$ \\
\hline
\end{tabular}

Rx: treatment

a $\mathrm{mmol} / \mathrm{L},{ }^{\mathrm{b}} \mathrm{mmHg},{ }^{\mathrm{c}} \mathrm{mL} / \mathrm{min} / 1.73 \mathrm{~m}^{2}$ 
Table 2 Risk factors associated with cardiovascular outcomes of interest

\begin{tabular}{|c|c|c|c|c|c|c|}
\hline \multirow[t]{2}{*}{ Variables } & \multicolumn{2}{|l|}{ Univariable analyses } & \multicolumn{4}{|c|}{ Multivariable analyses } \\
\hline & OR $(95 \% \mathrm{Cl})$ & p-value & OR $(95 \% \mathrm{CI})$ & p-value & ROC & $95 \% \mathrm{Cl}$ \\
\hline \multicolumn{7}{|c|}{ Cardiovascular disease (composite) } \\
\hline Female sex & $0.50(0.35-0.71)$ & $<0.001$ & $0.90(0.46-1.78)$ & 0.764 & 0.88 & $0.84-0.92$ \\
\hline Age (years) & $1.08(1.07-1.09)$ & $<0.001$ & $1.06(1.03-1.09)$ & $<0.001$ & & \\
\hline Diabetes duration group & $1.12(1.09-1.15)$ & $<0.001$ & $1.05(1.01-1.10)$ & 0.018 & & \\
\hline HbA1c (\%) & $1.04(0.95-1.15)$ & 0.386 & & & & \\
\hline HDL-cholesterol (mmol/L) & $0.36(0.21-0.62)$ & $<0.001$ & $0.43(0.21-0.90)$ & 0.025 & & \\
\hline Systolic BP (mmHg) & $1.03(1.02-1.04)$ & $<0.001$ & & & & \\
\hline Diastolic BP (mmHg) & $0.98(0.97-1.00)$ & 0.073 & $0.96(0.93-1.00)$ & 0.048 & & \\
\hline BMI categories & $1.00(0.97-1.03)$ & 0.937 & & & & \\
\hline Ever smoked & $3.39(2.32-4.95)$ & $<0.001$ & $2.40(1.26-4.58)$ & 0.008 & & \\
\hline Albuminuria & $2.30(1.49-3.56)$ & $<0.001$ & & & & \\
\hline $\mathrm{eGFR}\left(\mathrm{mL} / \mathrm{min} / 1.73 \mathrm{~m}^{2}\right)$ & $0.96(0.96-0.97)$ & $<0.001$ & & & & \\
\hline Antihypertensive Rx & $9.74(6.54-14.49)$ & $<0.001$ & $2.44(1.15-5.18)$ & 0.020 & & \\
\hline Lipid lowering Rx & $10.13(6.76-15.17)$ & $<0.001$ & & & & \\
\hline Retinopathy & $5.07(3.53-7.28)$ & $<0.001$ & & & & \\
\hline \multicolumn{7}{|l|}{ Stroke } \\
\hline Female sex & $0.33(0.15-0.72)$ & 0.006 & $0.49(0.16-1.47)$ & 0.201 & 0.81 & $0.74-0.88$ \\
\hline Age (years) & $1.06(1.04-1.09)$ & $<0.001$ & $1.05(1.01-1.08)$ & 0.006 & & \\
\hline Diabetes duration group & $1.08(1.03-1.12)$ & $<0.001$ & & & & \\
\hline $\mathrm{HbA} 1 \mathrm{c}(\%)$ & $1.17(0.99-1.38)$ & 0.062 & & & & \\
\hline HDL-cholesterol (mmol/L) & $0.26(0.09-0.77)$ & 0.015 & & & & \\
\hline Systolic BP (mmHg) & $1.02(1.00-1.04)$ & 0.016 & & & & \\
\hline Diastolic BP (mmHg) & $1.00(0.97-1.04)$ & 0.928 & & & & \\
\hline BMI categories & $1.02(0.96-1.10)$ & 0.514 & & & & \\
\hline Ever smoked & $2.32(1.10-4.92)$ & 0.027 & & & & \\
\hline Albuminuria & $2.27(0.97-5.31)$ & 0.059 & & & & \\
\hline $\mathrm{eGFR}\left(\mathrm{mL} / \mathrm{min} / 1.73 \mathrm{~m}^{2}\right)$ & $0.97(0.96-0.99)$ & $<0.001$ & $0.98(0.96-1.00)$ & 0.030 & & \\
\hline Antihypertensive Rx & $7.85(3.47-17.74)$ & $<0.001$ & & & & \\
\hline Lipid lowering Rx & $7.54(3.35-16.95)$ & $<0.001$ & & & & \\
\hline Retinopathy & $3.87(1.88-7.96)$ & $<0.001$ & & & & \\
\hline \multicolumn{7}{|l|}{ Myocardial infarction } \\
\hline Female sex & $0.41(0.23-0.72)$ & 0.002 & $0.97(0.39-2.41)$ & 0.943 & 0.90 & $0.87-0.94$ \\
\hline Age (years) & $1.08(1.06-1.10)$ & $<0.001$ & $1.09(1.05-1.13)$ & $<0.001$ & & \\
\hline Diabetes duration group & $1.12(1.08-1.17)$ & $<0.001$ & & & & \\
\hline $\mathrm{HbA1c}(\%)$ & $0.96(0.82-1.13)$ & 0.647 & & & & \\
\hline HDL-cholesterol (mmol/L) & $0.24(0.10-0.58)$ & 0.002 & $0.20(0.06-0.68)$ & 0.010 & & \\
\hline Systolic BP (mmHg) & $1.03(1.02-1.05)$ & $<0.001$ & & & & \\
\hline Diastolic BP (mmHg) & $1.01(0.98-1.03)$ & 0.707 & & & & \\
\hline BMI categories & $1.01(0.95-1.06)$ & 0.842 & & & & \\
\hline Ever smoked & $2.31(1.30-4.10)$ & 0.004 & & & & \\
\hline Albuminuria & $2.20(1.15-4.21)$ & 0.017 & & & & \\
\hline $\mathrm{eGFR}\left(\mathrm{mL} / \mathrm{min} / 1.73 \mathrm{~m}^{2}\right)$ & $0.97(0.96-0.98)$ & $<0.001$ & & & & \\
\hline Antihypertensive Rx & $23.91(10.12-56.49)$ & $<0.001$ & $5.06(1.38-18.54)$ & 0.014 & & \\
\hline Lipid lowering Rx & $18.21(8.14-40.73)$ & $<0.001$ & & & & \\
\hline Retinopathy & $3.67(2.12-6.35)$ & $<0.001$ & & & & \\
\hline
\end{tabular}


Table 2 (continued)

\begin{tabular}{|c|c|c|c|c|c|c|}
\hline \multirow[t]{2}{*}{ Variables } & \multicolumn{2}{|l|}{ Univariable analyses } & \multicolumn{4}{|c|}{ Multivariable analyses } \\
\hline & OR $(95 \% \mathrm{Cl})$ & p-value & OR $(95 \% \mathrm{Cl})$ & p-value & ROC & $95 \% \mathrm{Cl}$ \\
\hline \multicolumn{7}{|c|}{ Coronary artery bypass graft/angioplasty } \\
\hline Female sex & $0.38(0.22-0.68)$ & 0.001 & $0.93(0.34-2.52)$ & 0.884 & 0.92 & $0.89-0.95$ \\
\hline Age (years) & $1.09(1.07-1.12)$ & $<0.001$ & $1.08(1.03-1.13)$ & 0.001 & & \\
\hline Diabetes duration group & $1.21(1.13-1.30)$ & $<0.001$ & & & & \\
\hline $\mathrm{HbA1c}(\%)$ & $0.96(0.81-1.12)$ & 0.586 & & & & \\
\hline HDL-cholesterol (mmol/L) & $0.27(0.11-0.67)$ & 0.005 & $0.23(0.06-0.92)$ & 0.038 & & \\
\hline Systolic BP (mmHg) & $1.03(1.01-1.04)$ & $<0.001$ & & & & \\
\hline Diastolic BP (mmHg) & $0.98(0.96-1.01)$ & 0.171 & & & & \\
\hline BMI categories & $1.03(0.98-1.09)$ & 0.263 & & & & \\
\hline Ever smoked & $2.18(1.25-3.81)$ & 0.006 & & & & \\
\hline Albuminuria & $1.82(0.93-3.59)$ & 0.082 & & & & \\
\hline $\operatorname{eGFR}\left(\mathrm{mL} / \mathrm{min} / 1.73 \mathrm{~m}^{2}\right)$ & $0.97(0.96-0.98)$ & $<0.001$ & & & & \\
\hline Antihypertensive Rx & $38.63(13.83-107.88)$ & $<0.001$ & $8.96(1.12-71.54)$ & 0.039 & & \\
\hline Lipid lowering Rx & $36.00(12.91-100.41)$ & $<0.001$ & & & & \\
\hline Retinopathy & $4.45(2.57-7.69)$ & $<0.001$ & & & & \\
\hline \multicolumn{7}{|l|}{ Peripheral vascular disease } \\
\hline Female sex & $0.73(0.46-1.16)$ & 0.180 & $1.08(0.49-2.39)$ & 0.851 & 0.85 & $0.81-0.90$ \\
\hline Age (years) & $1.07(1.05-1.09)$ & $<0.001$ & $1.04(1.01-1.07)$ & 0.005 & & \\
\hline Diabetes duration group & $1.11(1.08-1.15)$ & $<0.001$ & & & & \\
\hline $\mathrm{HbA1c}(\%)$ & $1.09(0.96-1.24)$ & 0.171 & & & & \\
\hline HDL-cholesterol (mmol/L) & $0.37(0.18-0.77)$ & 0.008 & & & & \\
\hline Systolic BP (mmHg) & $1.02(1.01-1.04)$ & $<0.001$ & & & & \\
\hline Diastolic BP (mmHg) & $0.97(0.95-0.99)$ & 0.009 & & & & \\
\hline BMI categories & $0.99(0.95-1.03)$ & 0.653 & & & & \\
\hline Ever smoked & $3.67(2.22-6.08)$ & $<0.001$ & & & & \\
\hline Albuminuria & $2.97(1.65-5.34)$ & $<0.001$ & & & & \\
\hline eGFR (mL/min/1.73 m²) & $0.96(0.95-0.97)$ & $<0.001$ & $0.97(0.96-0.99)$ & 0.002 & & \\
\hline Antihypertensive Rx & $5.26(3.25-8.53)$ & $<0.001$ & & & & \\
\hline Lipid lowering Rx & $5.22(3.21-8.46)$ & $<0.001$ & & & & \\
\hline Retinopathy & $6.41(3.95-10.41)$ & $<0.001$ & $2.47(1.06-5.74)$ & 0.036 & & \\
\hline \multicolumn{7}{|l|}{ Congestive cardiac failure } \\
\hline Female sex & $1.00(0.36-2.78)$ & 0.964 & $1.51(0.30-7.47)$ & 0.614 & 0.90 & $0.84-0.95$ \\
\hline Age (years) & $1.10(1.06-1.14)$ & $<0.001$ & $1.15(1.05-1.25)$ & 0.002 & & \\
\hline Diabetes duration group & $1.16(1.05-1.29)$ & 0.004 & & & & \\
\hline $\mathrm{HbA1c}(\%)$ & $0.97(0.70-1.34)$ & 0.858 & & & & \\
\hline HDL-cholesterol (mmol/L) & $1.68(0.90-3.16)$ & 0.104 & & & & \\
\hline Systolic BP (mmHg) & $1.02(0.99-1.05)$ & 0.157 & & & & \\
\hline Diastolic BP (mmHg) & $0.97(0.92-1.02)$ & 0.195 & & & & \\
\hline BMI categories & $1.20(1.05-1.38)$ & 0.008 & & & & \\
\hline Ever smoked & $1.40(0.50-3.90)$ & 0.515 & & & & \\
\hline Albuminuria & $5.30(1.36-20.70)$ & 0.016 & & & & \\
\hline $\mathrm{eGFR}\left(\mathrm{mL} / \mathrm{min} / 1.73 \mathrm{~m}^{2}\right)$ & $0.95(0.94-0.97)$ & $<0.001$ & & & & \\
\hline Antihypertensive Rx & $37.42(4.90-285.81)$ & $<0.001$ & & & & \\
\hline Lipid Lowering Rx & $6.70(2.12-21.21)$ & 0.001 & & & & \\
\hline Retinopathy & $20.75(4.65-92.51)$ & $<0.001$ & & & & \\
\hline
\end{tabular}

Rx: treatment 
respectively]. The model's discriminatory ability was demonstrated with area under the ROC curve of 0.88 (95\% CI 0.84, 0.92) (Table 2).

When stroke was considered, there was significant positive association with increasing age [aOR 1.05 (95\% CI 1.01, 1.08)]. Increasing eGFR was negatively associated with stroke [aOR 0.98 (95\% CI 0.96, 1.00)]. The area under the ROC curve was 0.81 (95\% CI 0.74, 0.88) (Table 2).

When the outcome of MI or CABG/angioplasty was considered, there were significant positive associations with increasing age [aOR 1.09 (95\% CI 1.05, $1.13)$ or aOR 1.08 (95\% CI 1.03, 1.13)] and antihypertensive therapy [aOR 5.06 (95\% CI 1.38, 18.54) or aOR 8.96 (95\% CI 1.12, 71.54)], and negative associations with increasing HDL-C [aOR 0.20 (95\% CI 0.06, 0.68) or aOR $0.23(95 \%$ CI $0.06,0.92)]$. The area under the ROC curve for MI was 0.90 (95\% CI $0.87,0.94)$ and for CABG/angioplasty, it was 0.92 (95\% CI $0.89,0.95)$ (Table 2).

When PVD was considered, there were significant positive associations with increasing age [aOR 1.04 (95\% CI 1.01, 1.07)], retinopathy [aOR 2.47 (95\% CI $1.06,5.74)$ ], and negative association with eGFR [aOR 0.97 (95\% CI 0.96, 0.99)]. The area under the ROC curve was 0.85 (95\% CI $0.81,0.90)$ (Table 2).

When the additional outcome of CCF was considered, there was significant association with increasing age [aOR 1.15 (95\% CI 1.05, 1.25)]. The area under the ROC curve was 0.90 (95\% CI 0.84, 0.95) (Table 2).

\section{Sensitivity analyses}

Adding diabetes centre type into the final multivariable CVD models had minimal impact on the associations. There was also no significant interaction between diabetes centre type and any atherosclerotic cardiovascular outcome. Further, excluding patients with CCF resulted in diastolic blood pressure and antihypertensive therapy being removed from the final parsimonious model for CVD (data not shown).

After multiple imputation for missing data there was an increase in the magnitude of the association between antihypertensive therapy and MI or CABG/ angioplasty [aOR 15.91 (95\% CI 7.65, 33.12; p < 0.001) and aOR 21.90 (95\% CI 9.79, 48.99; p < 0.001) respectively] and HDL-cholesterol was no longer significantly associated with CABG/angioplasty [aOR 0.45 (95\% CI 0.19, 1.08; p 0.072)] (Additional file 3: Table S1).

\section{Population attributable risks for factors associated with cardiovascular outcomes}

In the study population, the estimated proportions of CVD attributable to diabetes duration $\geq 20$ years, use of antihypertensive therapy and smoking were 6.5\% (95\% CI $1.4,11.6), 5.1 \%(95 \%$ CI $0.9,9.3)$ and $3.9 \%$ (95\% CI 1.0, 6.7), respectively. The estimated proportion of PVD attributable to presence of retinopathy was $2.7 \%(95 \%$ CI 0.2, 5.2). The estimated proportions of MI or CABG/ angioplasty attributable to use of antihypertensive therapy were $4.8 \%(95 \%$ CI $1.8,7.8)$ and $11.2 \%$ (95\% CI 5.0, 17.5), respectively (Additional file 6: Table S4).

\section{Discussion}

This study reports for the first time the large burden of cardiovascular risk factors among patients with type 1 diabetes attending diabetes centres across Australia. Furthermore it shows that a group of traditional cardiovascular risk factors (age, sex, HDL-cholesterol level, smoking status, diastolic blood pressure and use of antihypertensive therapy) and diabetes specific risk factors (type 1 diabetes duration), provide good discriminatory ability for the presence of CVD. The individual outcomes of MI, CABG/angioplasty and CCF share similar associations, while stroke is also associated with declining renal function and PVD is associated with declining renal function and retinopathy. This suggests that information required for cardiovascular risk stratification among patients with type 1 diabetes may not differ substantively from other high risk populations aside from the need to consider diabetes duration.

The significant non-linear association between diabetes duration and CVD (independent of patient age) and the threshold effect seen at approximately 20 years, is an important finding and consistent with previous modelling, prospective cohort and registry studies $[12,13,22$, 33-35]. Indeed, population based cohort studies and national registry studies have all observed increased rates of CVD with longer diabetes duration. Some have also reported that CVD becomes the leading cause of death after about 20 years duration [12, 13, 22, 34, 35]. The substantive PAR related to longer diabetes duration strongly supports the assessment and management of cardiovascular risk among people with long diabetes duration irrespective of their current age and the older age thresholds recommended by current $\mathrm{CVD}$ guidelines.

The negative association of HDL-cholesterol with CVD, MI and CABG/angioplasty [aOR 0.43 (95\% CI 0.21, 0.90); 0.20 (95\% CI $0.06,0.68)$ and 0.23 (95\% CI $0.06,0.92)$ 
respectively] is in keeping with current understanding of a protective role for HDL-cholesterol and HDL function $[1,36-40]$. While it is unknown whether increasing HDL-cholesterol will improve cardiovascular outcomes among patients with type 1 diabetes, the importance of this lipid variable for risk stratification is consistent with data from the Framingham Heart Study and a number of meta-analyses which have also reported an inverse association with CVD in other populations [36-38, 41]. The observation that pharmacotherapies were strongly associated with CVD likely relates to secondary prevention strategies.

The lack of an independent positive association between CVD and HbA1c, systolic blood pressure, BMI, albuminuria or negative association with renal function was unexpected. In particular, our finding of no association with HbA1c conflicts with other evidence of a linear relationship between hyperglycaemia or glycaemic exposure and cardiovascular risk [33, 42-48]. This may be explained by differences in the study designs as we were unable to assess glycaemic control over time. We also noted no significant difference in glycaemic control among adults with or without cardiovascular disease ( $\mathrm{p}$ 0.386; Table 1).

Systolic blood pressure, albuminuria and declining eGFR were significantly associated with increased risk of CVD in univariable analysis [OR 1.03 (95\% CI 1.02, 1.04), OR 2.30 (95\% CI 1.49, 3.56) and OR 0.96 (95\% CI 0.96, $0.97)$ respectively], but not in the multivariable analysis, suggesting these effects were accounted for by other variables in the model. Interestingly, the mean systolic and diastolic blood pressures among all patients and among those with CVD were within or close to recommended blood pressure targets measuring $124 \pm 17$ and $74 \pm 10 \mathrm{mmHg}$, and $132 \pm 21$ and $72 \pm 10 \mathrm{mmHg}$ respectively. Albuminuria was also noted to be prevalent in $31.1 \%$ of our cohort, affecting around half $(47.9 \%)$ of the patients with a history of CVD and is consistent with international estimates of $28-52 \%$ prevalence among patients with type 1 diabetes $[49,50]$. This highlights the current prioritisation of blood pressure control among diabetes centres in Australia [1,2] as well as the importance of routine screening for renal dysfunction and albuminuria.

Our finding that $38.5 \%$ of adult patients with type 1 diabetes had been smokers is consistent with a recent report that $38 \%$ of all Australians over 14 years of age have been smokers [51]. As expected, the proportion was much higher among those patients with a history CVD (64.2\%), reinforcing the need for diabetes centres to offer patients assistance with smoking cessation efforts.

While elevated $\mathrm{BMI}$ is recognised as an independent risk factor for CVD in the general population [14-18], this relationship is not firmly established in patients with type 1 diabetes [52] and no association was noted in our analyses. Nonetheless, the finding that $56.4 \%$ of patients with type 1 diabetes were either overweight or obese is alarming but consistent with other studies in this population that report rates as high as 78\% [53-55]. In addition, we found that female sex was not independently associated with any cardiovascular outcome. This supports the premise that the protective effect of female sex on cardiovascular disease is negated among women with type 1 diabetes as reported by previous cohort and registry studies $[5,12,13]$.

The association between CVD and diastolic blood pressure is complex and may be impacted by patient age, arterial stiffness, vascular resistance, endothelial dysfunction, diastolic dysfunction and antihypertensive therapy $[25,26,56-58]$. This may be of particular relevance to our heterogeneous cohort ranging from 18 to 91 years of age, including patients with CCF and those taking multiple antihypertensive agents. The observed negative association between diastolic blood pressure and CVD may also represent reverse causation [59-63]. It was thus not surprising that diastolic blood pressure was removed from the prediction model when patients with CCF were excluded.

The finding that diabetic retinopathy and declining renal function was associated with peripheral vascular disease was not surprising and may relate to shared risk factors [64-66]. In our cross-sectional study, microvascular complications such as retinopathy or nephropathy provided an indication of long term risk factor exposure, but cohort studies have suggested PVD may also predict cardiovascular outcomes and end stage kidney disease $[64,67]$. Further, the negative association between renal function and stroke that we observed is in keeping with studies among the general population [68-71]. However, we found no independent association between stroke and albuminuria in contrast to prior studies [72-77].

A strength of this analysis includes the large dataset of patients with type 1 diabetes taken from a nation-wide benchmarking activity. Furthermore, participants are likely to be representative of patients attending diabetes centres throughout Australia as data were collected from every state and territory. Data were also collected for a broad range of cardiovascular risk factors and clinically significant outcomes, with consideration of non-linear associations and precision of risk prediction using area under the ROC curve. Key study limitations comprise the cross-sectional nature of data collection, possible referral bias, and the reliance on healthcare worker reports as we were unable to independently verify diagnoses, treatments or biochemistry. Also, the pre-specified clinical questionnaire in ANDA did not provide scope to 
differentiate those patients who were normotensive or had normal lipid profiles due to medication or if pharmacotherapy was solely part of secondary prevention strategies, and these groups may confer different degrees of cardiovascular risk. Another limitation is that albuminuria was defined by a single biochemistry result within the 12 months prior to participation in ANDA. Single false positive results or resolution of albuminuria with blockade of the renin-angiotensin-aldosterone-system therefore could not be captured by this study. The association between adiposity and CVD was assessed only with BMI, but other measures such as waist circumference may add to future studies. Finally, the calculation of PAR was based on the assumption that there was a causal relationship between the risk factors identified in our study and CVD outcomes. Despite these limitations, this study provides important data on CVD among a large population with type 1 diabetes and informs future longitudinal analyses of cardiovascular risk stratification. Our findings also suggest that future cardiovascular risk stratification models will need to examine the impact of diabetes specific risk factors for populations with type 1 diabetes using the 'Transparent Reporting of a multivariable prediction model for Individual Prognosis or Diagnosis' (TRIPOD) statement [78].

\section{Conclusions}

Our study demonstrates that the adult population with type 1 diabetes attending diabetes centres bears a significant cardiovascular burden. Further, analysis reveals associations between a number of traditionally considered and diabetes specific risk factors with CVD, which together provide good discriminatory ability for presence of disease. Given the substantial population risk of CVD attributable to long diabetes duration, the impact of new cardiovascular risk stratification tools and interventions to manage risk factors before and after 20 years duration will need to be further assessed by prospective studies.

\section{Additional files}

Additional file 1. 'ANDA-AQCA 2015' provides the questionnaire that was completed as part of the Australian Quality Clinical Audit [AQCA].

Additional file 2. 'ANDA-AQCA 2015 Data Definitions' outlines the definitions used by healthcare professionals who completed the questionnaire.

Additional file 3: Table S1. Multiple imputation for cardiovascular outcomes of interest.

Additional file 4: Table S2. Missing data for cardiovascular risk factors and outcomes of interest.

Additional file 5: Table S3. a Distribution of variables for cardiovascular outcomes of interest and b Distribution of variables for congestive cardiac failure.

Additional file 6: Table S4. Population attributable risk for cardiovascular outcomes of interest.

\section{Abbreviations}

ANDA: Australian National Diabetes Audit; aOR: adjusted odds ratio; AQCA: Australian Quality Clinical Audit; BMl: body mass index; BP: blood pressure; CABG: coronary artery bypass graft; CCF: congestive cardiac failure; CKD-EPI: chronic kidney disease epidemiology collaboration; CVD: cardiovascular disease; eGFR: estimated glomerular filtration rate; HbA1c: glycated haemoglobin; HDL-C: high density lipoprotein-cholesterol; IQR: interquartile range (25th-75th percentile); LDL-C: low density lipoprotein-cholesterol; HDL-C: high density lipoprotein-cholesterol; MI: myocardial infarction; NADC: National Association of Diabetes Centres; PVD: peripheral vascular disease; ROC: receiver operating characteristic; Rx: treatment; SD: standard deviation; Total-C: total-cholesterol; TRIPOD: Transparent Reporting of a multivariable prediction model for Individual Prognosis or Diagnosis.

\section{Authors' contributions}

AP drafted the manuscript and performed statistical analysis under the supervision of senior authors, SZ and AE. Manuscript drafting and review was assisted by SR, NN, DL, NW, SA and SZ. SR also provided advice regarding statistical analysis. All authors read and approved the final manuscript.

\section{Author details}

${ }^{1}$ School of Public Health and Preventive Medicine, Monash University, 5th Floor, The Alfred Centre, 99 Commercial Road, Melbourne, VIC 3004, Australia. 2 Diabetes and Vascular Medicine Unit, Monash Health, Clayton, VIC 3168, Australia. ${ }^{3}$ Department of Medicine, The University of Melbourne, Melbourne, VIC 3010, Australia.

\section{Acknowledgements}

We thank the participating diabetes centres for their time and generous contribution to the Australian National Diabetes Audit.

\section{Competing interests}

$A P, A E$, SR and NN report no competing interests in relation to this study. $D L$ reports having received honoraria and study grants from AbbVie, AstraZeneca, Bayer, Bristol Myers Squibb, Pfizer, Sanofi and Shire. NW reports institutional contract work outside the submitted work from AstraZeneca, Novo Nordisk, Roche, Eli Lilly and MSD Australia. SA reports past participation in advisory boards and/or receiving honoraria outside the submitted work from GlaxoSmithKline, Novartis, AstraZeneca/Bristol-Myers Squibb Australia, Eli Lilly Australia, Janssen Cilag, Merck Sharp \& Dohme (Australia), Sanofi Aventis, Novo Nordisk and Servier Laboratories. SZ reports institutional contract work outside the submitted work from AstraZeneca, Novo Nordisk and MSD Australia.

\section{Availability of data and materials}

The datasets used and/or analysed during the current study are available from the ANDA secretariat on reasonable request in line with the research data enquiry procedures.

\section{Consent for publication}

Not applicable.

\section{Ethics approval and consent to participate}

Ethics approval was provided by Monash Health Human Research Ethics Committee (Monash Health Reference: RES-17-0000-164L).

\section{Funding}

The Commonwealth Department of Health and Ageing funds the Australian National Diabetes Audit. This research has received no specific grant from any funding agency in the public, commercial or not-for profit sectors.

\section{Publisher's Note}

Springer Nature remains neutral with regard to jurisdictional claims in published maps and institutional affiliations.

Received: 15 March 2018 Accepted: 26 May 2018

Published online: 02 June 2018 


\section{References}

1. National Vascular Disease Prevention Alliance. Guidelines for the management of absolute cardiovascular disease risk. 2012. https://www.aihw. gov.au/getmedia/0ce5f234-0abf-41b9-a392-be5dd1e94c54/17034.pdf. aspx?inline=true. Accessed 5 Mar 2018.

2. Australian Institute of Health and Welfare 2014. Cardiovascular disease, diabetes and chronic kidney disease-Australian facts: prevalence and incidence. Cardiovascular, diabetes and chronic kidney disease series no. 2. Cat. no. CDK 2. Canberra: AlHW. https://www.aihw.gov.au/getme dia/0ce5f234-0abf-41b9-a392-be5dd1e94c54/17034.pdf.aspx?inlin $\mathrm{e}=$ true. Accessed 5 Mar 2018

3. Schnell O, Cappuccio F, Genovese S, Standl E, Valensi P, Ceriello A. Type 1 diabetes and cardiovascular disease. Cardiovasc Diabetol. 2013;12(1):156.

4. de Ferranti SD, de Boer IH, Fonseca V, Fox CS, Golden SH, Lavie CJ, et al. Type 1 diabetes mellitus and cardiovascular disease: a scientific statement from the American Heart Association and American Diabetes Association. Diab Care. 2014;37(10):2843-63.

5. Laing SP, Swerdlow AJ, Slater SD, Burden AC, Morris A, Waugh NR, et al. Mortality from heart disease in a cohort of 23,000 patients with insulintreated diabetes. Diabetologia. 2003;46(6):760-5. https://doi.org/10.1007/ s00125-003-1116-6.

6. Morrish NJ, Wang SL, Stevens LK, Fuller JH, Keen H. Mortality and causes of death in the WHO multinational study of vascular disease in diabetes. Diabetologia. 2001;44(Suppl 2):S14-21.

7. Soedamah-Muthu SS, Fuller JH, Mulnier HE, Raleigh VS, Lawrenson RA, Colhoun HM. High risk of cardiovascular disease in patients with type 1 diabetes in the U.K.: a cohort study using the general practice research database. Diab Care. 2006;29(4):798-804. http://care.diabetesjournal s.org/content/29/4/798.long. Accessed 15 May 2018.

8. Goff DC, Lloyd-Jones DM, Bennett G, Coady S, D'Agostino RB, Gibbons R, et al. 2013 ACC/AHA guideline on the assessment of cardiovascular risk. A report of the American College of Cardiology/American Heart Association Task Force on practice guidelines. Circulation. 2014;129:S49-73. http://circ.ahajournals.org/content/129/25_suppl_2/S49.long. Accessed 16 May 2018.

9. Piepoli MF, Hoes AW, Agewall S, Albus C, Brotons C, Catapano AL, et al. 2016 European guidelines on cardiovascular disease prevention in clinical practice. The sixth joint task force of the European Society of Cardiology and other societies on cardiovascular disease prevention in clinical practice (constituted by representatives of 10 societies and by invited experts). Developed with the special contribution of the European Association for Cardiovascular Prevention \& Rehabilitation (EACPR). Eur Heart J. 2016;37(29):2315-81.

10. National Institute for Health and Care Excellence. Cardiovascular disease: risk assessment and reduction, including lipid modification. Clinical guideline [CG181]. 2014. http://www.nice.org.uk/Guidance/CG181. Accessed 17 Feb 2018.

11. Jaiswal M, Divers J, Urbina EM, Dabelea D, Bell RA, Pettitt DJ, et al. Cardiovascular autonomic neuropathy in adolescents and young adults with type 1 and type 2 diabetes: the SEARCH for diabetes in youth cohort study. Pediatr Diab. 2018;19(4):680-9. https://doi.org/10.1111/pedi.12633.

12. Skrivarhaug T, Bangstad HJ, Stene LC, Sandvik L, Hanssen KF, Joner G. Long-term mortality in a nationwide cohort of childhood-onset type 1 diabetic patients in Norway. Diabetologia. 2006;49(2):298-305. https:// doi.org/10.1007/s00125-005-0082-6.

13. Secrest AM, Becker DJ, Kelsey SF, Laporte RE, Orchard TJ. Cause-specific mortality trends in a large population-based cohort with long-standing childhood-onset type 1 diabetes. Diabetes. 2010;59(12):3216-22. http:// diabetes.diabetesjournals.org/content/59/12/3216. Accessed 14 May 2018

14. Hubert HB, Feinleib M, McNamara PM, Castelli WP. Obesity as an independent risk factor for cardiovascular disease: a 26-year follow-up of participants in the Framingham heart study. Circulation. 1983;67(5):968 77. http://circ.ahajournals.org/content/67/5/968.long. Accessed 12 May 2018

15. Manson JE, Colditz GA, Stampfer MJ, Willett WC, Rosner B, Monson RR, et al. A prospective study of obesity and risk of coronary heart disease in women. N Engl J Med. 1990;322(13):882-9. https://doi.org/10.1056/ NEJM199003293221303.

16. Wilson PW, D'Agostino RB, Sullivan L, Parise H, Kannel WB. Overweight and obesity as determinants of cardiovascular risk: the Framingham experience. Arch Intern Med. 2002;162(16):1867-72. https://jamanetwor k.com/journals/jamainternalmedicine/fullarticle/212796. Accessed 14 May 2018.

17. Malik S, Wong ND, Franklin SS, Kamath TV, L'Italien GJ, Pio JR, et al. Impact of the metabolic syndrome on mortality from coronary heart disease, cardiovascular disease, and all causes in United States adults. Circulation. 2004:110(10):1245-50.

18. Yusuf S, Hawken S, Ounpuu S, Dans T, Avezum A, Lanas F, et al. Effect of potentially modifiable risk factors associated with myocardial infarction in 52 countries (the INTERHEART study): case-control study. Lancet. 2004;364(9438):937-52. https://www.thelancet.com/journals/lancet/artic e/PIIS0140-6736(04)17018-9/fulltext. Accessed 14 May 2018.

19. Craig ME, Twigg SM, Donaghue KC, Cheung NW, Cameron FJ, Conn J, et al for the Australian Type 1 Diabetes Guidelines Expert Advisory Group. National evidence-based clinical care guidelines for type 1 diabetes in children, adolescents and adults. In: Australian Government Department of Health and Ageing. Canberra 2011. https://www.nhmrc.gov.au/_files nhmrc/publications/attachments/ext004 type1 diabetes children adolescents_adults.pdf. Accessed 5 Mar 2018.

20. Zgibor JC, Piatt GA, Ruppert K, Orchard TJ, Roberts MS. Deficiencies of cardiovascular risk prediction models for type 1 diabetes. Diab Care. 2006;29(8):1860-5. http://care.diabetesjournals.org/content/diaca re/29/8/1860.full.pdf. Accessed 10 May 2018.

21. Vistisen D, Andersen GS, Hansen CS, Hulman A, Henriksen JE, BechNielsen $\mathrm{H}$, et al. Prediction of first cardiovascular disease event in type 1 diabetes mellitus: the steno type 1 risk engine. Circulation. 2016:133(11):1058-66. http://circ.ahajournals.org/content/133/11/1058. long. Accessed 15 May 2018.

22. Cederholm J, Eeg-Olofsson K, Eliasson B, Zethelius B, Gudbjornsdottir S. A new model for 5-year risk of cardiovascular disease in type 1 diabetes; from the Swedish National Diabetes Register (NDR). Diab Med. 2011;28(10):1213-20. https://doi.org/10.1111/j.1464-5491.2011.03342.x.

23. Zgibor JC, Ruppert K, Orchard TJ, Soedamah-Muthu SS, Fuller J, Chaturvedi $\mathrm{N}$, et al. Development of a coronary heart disease risk prediction model for type 1 diabetes: the Pittsburgh CHD in type 1 diabetes risk model. Diab Res Clin Pract. 2010:88(3):314-21.

24. Hernández M, López C, Real J, Valls J, Ortega-Martinez de Victoria E, Vázquez F, et al. Preclinical carotid atherosclerosis in patients with latent autoimmune diabetes in adults (LADA), type 2 diabetes and classical type 1 diabetes. Cardiovasc Diabetol. 2017;16:94.

25. Ferreira I, Hovind P, Schalkwijk CG, Parving HH, Stehouwer CDA, Rossing P. Biomarkers of inflammation and endothelial dysfunction as predictors of pulse pressure and incident hypertension in type 1 diabetes: a 20 year life-course study in an inception cohort. Diabetologia. 2018;61(1):231-41. https://doi.org/10.1007/s00125-017-4470-5.

26. Bradley TJ, Slorach C, Mahmud FH, Dunger DB, Deanfield J, Deda L, et al. Early changes in cardiovascular structure and function in adolescents with type 1 diabetes. Cardiovasc Diabetol. 2016;15:31.

27. Swasey KK, Orchard TJ, Costacou T. Trends in cardiovascular risk factor management in type 1 diabetes by sex. J Diab Compl. 2018;32(4):411-7. https://www.jdcjournal.com/article/S1056-8727(17)30931-5/fulltext. Accessed 14 May 2018.

28. Levey AS, Stevens LA, Schmid CH, Zhang YL, Castro AF 3rd, Feldman HI, et al. A new equation to estimate glomerular filtration rate. Ann Intern Med. 2009;150(9):604-12

29. Maple-Brown LJ, Hughes JT, Ritte R, Barzi F, Hoy WE, Lawton PD, et al. Progression of kidney disease in indigenous Australians: the eGFR follow-up study. Clin J Am Soc Nephrol. 2016;11(6):993-1004.

30. Maple-Brown LJ, Cunningham J, Hodge AM, Weeramanthri T, Dunbar $T$, Lawton $P D$, et al. High rates of albuminuria but not of low eGFR in urban indigenous Australians: the DRUID Study. BMC Public Health. 2011;11(1):346.

31. Johnson DW, Jones GRD, Mathew TH, Ludlow MJ, Doogue MP, Jose MD, et al. Chronic kidney disease and automatic reporting of estimated glomerular filtration rate: new developments and revised recommendations. Med J Aust. 2012. 197(4):222-3. https://www.mja.com.au/journ al/2012/197/4/chronic-kidney-disease-and-automatic-reporting-estim ated-glomerular-filtration. Accessed 4 May 2018.

32. Gordis L. Epidemiology. 2nd ed. Philadelphia:W.B. Saunders Company; 2000. 
33. Nathan DM, Genuth S, Lachin J, Cleary P, Crofford O, Davis M, et al. The effect of intensive treatment of diabetes on the development and progression of long-term complications in insulin-dependent diabetes mellitus. N Engl J Med. 1993;329(14):977-86. https://www.nejm.org/ doi/10.1056/NEJM199309303291401?url_ver=Z39.88-2003\&rfr_ id=ori:rid:crossref.org\&rfr_dat=cr_pub\%3dwww.ncbi.nlm.nih.gov. Accessed 14 May 2018.

34. Morimoto A, Onda Y, Nishimura R, Sano H, Utsunomiya K, Tajima N. Cause-specific mortality trends in a nationwide population-based cohort of childhood-onset type 1 diabetes in Japan during 35 years of follow-up: the DERI mortality study. Diabetologia. 2013;56(10):2171-5. https://doi. org/10.1007/s00125-013-3001-2.

35. Livingstone SJ, Looker HC, Hothersall EJ, Wild SH, Lindsay RS, Chalmers J, et al. Risk of cardiovascular disease and total mortality in adults with type 1 diabetes: Scottish registry linkage study. PLoS Med. 2012;9(10):e1001321.

36. Gordon T, Castelli WP, Hjortland MC, Kannel WB, Dawber TR. High density lipoprotein as a protective factor against coronary heart disease: the Framingham study. Am J Med. 1977;62(5):707-14. https://www.amjme d.com/article/0002-9343(77)90874-9/pdf. Accessed 15 May 2018.

37. Cooney MT, Dudina A, De Bacquer D, Wilhelmsen L, Sans S, Menotti $A$, et al. $\mathrm{HDL}$ cholesterol protects against cardiovascular disease in both genders, at all ages and at all levels of risk. Atherosclerosis. 2009;206(2):611-6. https://www.atherosclerosis-journal.com/article/ S0021-9150(09)00163-4/fulltext. Accessed 14 May 2018.

38. Di Angelantonio E, Sarwar N, Perry P, Kaptoge S, Ray KK, Thompson A, et al. Major lipids, apolipoproteins, and risk of vascular disease. JAMA. 2009;302(18):1993-2000.

39. Emerging risk factors collaboration, De Angelantonio E, Gao P, Pennells L, Kaptoge S, Caslake M, et al. Lipid-related markers and cardiovascular disease prediction. JAMA. 2012;307(23):2499-506.

40. Heier M, Borja MS, Brunborg C, Seljeflot I, Margeirsdottir HD, Hanssen KF, et al. Reduced HDL function in children and young adults with type 1 diabetes. Cardiovasc Diabetol. 2017;16:85.

41. Propsective studies collaboration, Lewington $S$, Whitlock G, Clarke R, Sherliker P, Emberson J, et al. Blood cholesterol and vascular mortality by age, sex, and blood pressure: a meta-analysis of individual data from 61 prospective studies with 55,000 vascular deaths. Lancet. 2007;370(9602):1829-39. https://www.thelancet.com/journals/lancet/ article/PIIS0140-6736(07)61778-4/fulltext. Accessed 14 May 2018.

42. Adler Al, Erqou S, Lima TA, Robinson AH. Association between glycated haemoglobin and the risk of lower extremity amputation in patients with diabetes mellitus-review and meta-analysis. Diabetologia. 2010:53(5):840-9. https://doi.org/10.1007/s00125-009-1638-7.

43. Larsen J, Brekke M, Sandvik L, Arnesen H, Hanssen KF, Dahl-Jorgensen K. Silent coronary atheromatosis in type 1 diabetic patients and its relation to long-term glycemic control. Diabetes. 2002;51 (8):2637-41. http://diabe tes.diabetesjournals.org/content/51/8/2637.long. Accessed 15 May 2018.

44. Eeg-Olofsson K, Cederholm J, Nilsson PM, Zethelius B, Svensson AM, Gudbjornsdottir S, et al. Glycemic control and cardiovascular disease in 7454 patients with type 1 diabetes: an observational study from the Swedish National Diabetes Register (NDR). Diab Care. 2010;33(7):1640-6.

45. Singer DE, Nathan DM, Anderson KM, Wilson PW, Evans JC. Association of $\mathrm{HbA1C}$ with prevalent cardiovascular disease in the original cohort of the Framingham heart study. Diabetes. 1992;41 (2):202-8. http://diabetes. diabetesjournals.org/content/41/2/202.long. Accessed 14 May 2018.

46. Zhao W, Katzmarzyk PT, Horswell R, Wang Y, Johnson J, Hu G. HbA1C and coronary heart disease risk among diabetic patients. Diab Care. 2014;37(2):428-35.

47. Chen YY, Lin YJ, Chong E, Chen PC, Chao TF, Chen SA, et al. The impact of diabetes mellitus and corresponding $\mathrm{HbA} 1 \mathrm{c}$ levels on the future risks of cardiovascular disease and mortality: a representative cohort study in Taiwan. PLoS ONE. 2015;10(4):e0123116. http://journals.plos.org/plosone/ article?id=10.1371/journal.pone.0123116. Accessed 14 May 2018.

48. Miller RG, Anderson SJ, Costacou T, Sekikawa A, Orchard TJ. Hemoglobin A1c and cardiovascular disease incidence in type 1 diabetes: an application of joint modeling of longitudinal and time-to-event data in the pittsburgh epidemiology of diabetes complications (EDC) study. Am J Epidemiol. 2018. https://academic.oup.com/aje/advance-article-abstract/ doi/10.1093/aje/kwx386/4831247? redirectedFrom=fulltext. Accessed 15 May 2018. (Epub ahead of print)
49. Newman DJ, Mattock MB, Dawnay AB, Kerry S, McGuire A, Yaqoob M, et al. Systematic review on urine albumin testing for early detection of diabetic complications. Health Technol Assess. 2005;9(30):iii-vi, xiii-163. https://www.journalslibrary.nihr.ac.uk/hta/hta9300\#/full-report. Accessed 15 May 2018

50. Warram JH, Gearin G, Laffel L, Krolewski AS. Effect of duration of type I diabetes on the prevalence of stages of diabetic nephropathy defined by urinary albumin/creatinine ratio. J Am Soc Nephrol. 1996;7(6):930-7. http://jasn.asnjournals.org/content/7/6/930.long. Accessed 15 May 2018.

51. Australian Institute of Health and Welfare 2017. National Drug Strategy Household Survey 2016: detailed findings. Drug Statistics series no. 31. Cat. no. PHE 214. Canberra: AlHW. https://www.aihw.gov.au/getme dia/15db8c15-7062-4cde-bfa4-3c2079f30af3/21028.pdf.aspx?inline=true. Accessed 5 Mar 2018.

52. Purnell JQ, Braffett BH, Zinman B, Gubitosi-Klug RA, Sivitz W, Bantle JP, et al. Impact of excessive weight gain on cardiovascular outcomes in type 1 diabetes: results from the diabetes control and complications trial/ epidemiology of diabetes interventions and complications (DCCT/EDIC) study. Diab Care. 2017;40(12):1756-62. http://care.diabetesjournals.org/ content/40/12/1756.long. Accessed 15 May 2018.

53. Conway B, Miller RG, Costacou T, Fried L, Kelsey S, Evans RW, et al. Temporal patterns in overweight and obesity in type 1 diabetes. Diab Med. 2010;27(4):398-404.

54. Price SA, Gorelik A, Fourlanos S, Colman PG, Wentworth JM. Obesity is associated with retinopathy and macrovascular disease in type 1 diabetes. Obes Res Clin Pract. 2014;8(2):e178-82. https://www.obesityresearch clinicalpractice.com/article/S1871-403X(13)00032-X/fulltext. Accessed 15 May 2018.

55. Holt SK, Lopushnyan N, Hotaling J, Sarma AV, Dunn RL, Cleary PA, et al. Prevalence of low testosterone and predisposing risk factors in men with type 1 diabetes mellitus: findings from the DCCT/EDIC. J Clin Endocrinol Metab. 2014;99(9):E1655-60.

56. Franklin SS. Beyond blood pressure: arterial stiffness as a new biomarker of cardiovascular disease. J Am Soc Hypertens. 2008;2(3):140-51. https:// www.ashjournal.com/article/S1933-1711(07)00194-5/fulltext. Accessed 15 May 2018.

57. Franklin SS, Wong ND. Hypertension and cardiovascular disease: contributions of the Framingham heart study. Glob Heart. 2013;8(1):49-57. https://www.sciencedirect.com/science/article/pii/S22118160120026 45?via\%3Dihub. Accessed 15 May 2018.

58. Marti CN, Gheorghiade M, Kalogeropoulos AP, Georgiopoulou W, Quyyumi AA, Butler J. Endothelial dysfunction, arterial stiffness, and heart failure. J Am Coll Cardiol. 2012;60(16):1455-69. https://www.sciencedir ect.com/science/article/pii/S0735109712025235?via\%3Dihub. Accessed 15 May 2018.

59. Hansson L, Zanchetti A, Carruthers SG, Dahlof B, Elmfeldt D, Julius S, et al. Effects of intensive blood-pressure lowering and low-dose aspirin in patients with hypertension: principal results of the hypertension optimal treatment (HOT) randomised trial. HOT study group. Lancet. 1998;351 (9118):1755-62. https://www.thelancet.com/journals/lancet/ article/PIIS0140-6736(98)04311-6/fulltext. Accessed 15 May 2018.

60. SPRINT Research Group, Wright JT Jr., Williamson JD, Whelton PK, Snyder JK, Sink KM, et al. A randomized trial of intensive versus standard blood-pressure control. N Engl J Med. 2015;373(22):2103-16. https:// www.nejm.org/doi/10.1056/NEJMoa1511939?url_ver=Z39.88-2003\&rfr_ id=ori:rid:crossref.org\&rfr_dat=cr_pub\%3dwww.ncbi.nlm.nih.gov. Accessed 15 May 2018.

61. Pepine CJ, Handberg EM, Cooper-DeHoff RM, Marks RG, Kowey P, Messerli $\mathrm{FH}$, et al. A calcium antagonist vs a non-calcium antagonist hypertension treatment strategy for patients with coronary artery disease. The international verapamil-trandolapril study (INVEST): a randomized controlled trial. JAMA. 2003;290(21):2805-16. https://jamanetwork.com/journals/ jama/fullarticle/197761. Accessed 15 May 2018.

62. Satish S, Zhang DD, Goodwin JS. Clinical significance of falling blood pressure among older adults. J Clin Epidemiol. 2001;54(9):961-7. https:// www.jclinepi.com/article/S0895-4356(01)00360-2/fulltext. Accessed 15 May 2018.

63. Vidal-Petiot E, Ford I, Greenlaw N, Ferrari R, Fox KM, Tardif JC, et al. Cardiovascular event rates and mortality according to achieved systolic and diastolic blood pressure in patients with stable coronary artery disease: an international cohort study. Lancet. 2016;388(10056):2142-52. https:// 
www.thelancet.com/journals/lancet/article/PIIS0140-6736(16)31326-5/ fulltext. Accessed 15 May 2018.

64. Mohammedi K, Potier L, Belhatem N, Matallah N, Hadjadj S, Roussel R, et al. Lower-extremity amputation as a marker for renal and cardiovascular events and mortality in patients with long standing type 1 diabetes. Cardiovasc Diabetol. 2016;15:5.

65. Mohammedi K, Woodward M, Hirakawa Y, Zoungas S, Williams B, Lisheng $L$, et al. Microvascular and macrovascular disease and risk for major peripheral arterial disease in patients with type 2 diabetes. Diab Care. 2016;39(10):1796-803. http://care.diabetesjournals.org/conte nt/39/10/1796.long. Accessed 15 May 2018.

66. Garimella PS, Hart PD, O'Hare A, DeLoach S, Herzog CA, Hirsch AT. Peripheral artery disease and CKD: a focus on peripheral artery disease as a critical component of CKD care. Am J Kidney Dis. 2012;60(4):641-54 https://www.ajkd.org/article/S0272-6386(12)00665-8/fulltext. Accessed 15 May 2018.

67. Criqui MH, Ninomiya JK, Wingard DL, Ji M, Fronek A. Progression of peripheral arterial disease predicts cardiovascular disease morbidity and mortality. J Am Coll Cardiol. 2008;52(21):1736-42. https://www.sciencedir ect.com/science/article/pii/S0735109708029598?via\%3Dihub. Accessed 15 May 2018.

68. Chronic kidney disease prognosis consortium, Matsushita K, van der Velde M, Astor BC, Woodward M, Levey AS, et al. Association of estimated glomerular filtration rate and albuminuria with all-cause and cardiovascular mortality in general population cohorts: a collaborative meta-analysis. Lancet. 2010;375(9731):2073-81. https://www.thelancet.com/journals/ lancet/article/PIIS0140-6736(10)60674-5/fulltext. Accessed 15 May 2018

69. Masson P, Webster AC, Hong M, Turner R, Lindley RI, Craig JC. Chronic kidney disease and the risk of stroke: a systematic review and meta-analysis. Nephrol Dial Transplant. 2015;30(7):1162-9. https://academic.oup.com/ ndt/article/30/7/1162/2324840. Accessed 15 May 2018.

70. Ovbiagele B, Bath PM, Cotton D, Sha N, Diener HC, PRoFESS investigators. Low glomerular filtration rate, recurrent stroke risk, and effect of reninangiotensin system modulation. Stroke. 2013;44(11):3223-5. http://strok e.ahajournals.org/content/44/11/3223.long. Accessed 15 May 2018.
71. Abramson JL, Jurkovitz CT, Vaccarino V, Weintraub WS, McClellan W. Chronic kidney disease, anemia, and incident stroke in a middleaged, community-based population: the ARIC study. Kidney Int. 2003;64(2):610-5. https://www.kidney-international.org/article/S0085 -2538(15)49368-8/fulltext. Accessed 15 May 2018.

72. Sandsmark DK, Messe SR, Zhang X, Roy J, Nessel L, Lee Hamm L, et al. Proteinuria, but not eGFR, predicts stroke risk in chronic kidney disease: chronic renal insufficiency cohort study. Stroke. 2015;46(8):2075-80.

73. Bouchi R, Babazono T, Nyumura I, Toya K, Hayashi T, Ohta M, et al. Is a reduced estimated glomerular filtration rate a risk factor for stroke in patients with type 2 diabetes? Hypertens Res. 2009;32(5):381-6. https:// www.nature.com/articles/hr200930. Accessed 15 May 2018.

74. Sundquist $K$, Li X. Type 1 diabetes as a risk factor for stroke in men and women aged 15-49: a nationwide study from Sweden. Diab Med. 2006;23(11):1261-7. https://doi.org/10.1111/j.1464-5491.2006.01959.x.

75. Hagg S, Thorn LM, Putaala J, Liebkind R, Harjutsalo V, Forsblom CM, et al. Incidence of stroke according to presence of diabetic nephropathy and severe diabetic retinopathy in patients with type 1 diabetes. Diab Care. 2013;36(12):4140-6. http://care.diabetesjournals.org/conte nt/36/12/4140.long. Accessed 15 May 2018.

76. Chang YT, Wu JL, Hsu CC, Wang JD, Sung JM. Diabetes and end-stage renal disease synergistically contribute to increased incidence of cardiovascular events: a nationwide follow-up study during 1998-2009. Diab Care. 2014;37(1):277-85. http://care.diabetesjournals.org/conte nt/37/1/277.long. Accessed 16 May 2018.

77. Tuomilehto J, Borch-Johnsen K, Molarius A, Forsen T, Rastenyte D, Sarti C, et al. Incidence of cardiovascular disease in Type 1 (insulin-dependent) diabetic subjects with and without diabetic nephropathy in Finland. Diabetologia. 1998;41(7):784-90. https://doi.org/10.1007/s001250050988.

78. Moons KG, Altman DG, Reitsma JB, loannidis JP, Macaskill P, Steyerberg EW, et al. Transparent reporting of a multivariable prediction model for individual prognosis or diagnosis (TRIPOD): explanation and elaboration. Ann Intern Med. 2015;162(1):W1-73. http://annals.org/aim/fullarticl e/2088542/transparent-reporting-multivariable-prediction-model-indiv idual-prognosis-diagnosis-tripod-explanation. Accessed 15 May 2018.
Ready to submit your research? Choose BMC and benefit from:

- fast, convenient online submission

- thorough peer review by experienced researchers in your field

- rapid publication on acceptance

- support for research data, including large and complex data types

- gold Open Access which fosters wider collaboration and increased citations

- maximum visibility for your research: over 100M website views per year

At BMC, research is always in progress.

Learn more biomedcentral.com/submissions 